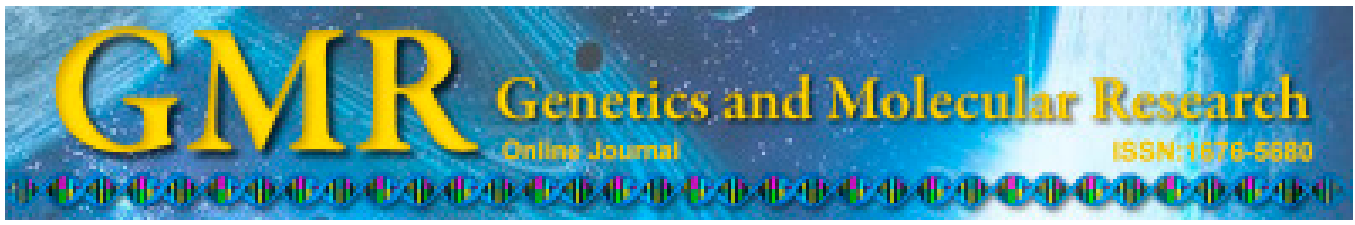

\title{
Ebp1 protein expression in cervical cancer tissue and its significance
}

\author{
L. Liu ${ }^{1 *}$, D.Y. Xu ${ }^{2 *}$, S.S. Yang ${ }^{2}$ and X.D. $\mathrm{Li}^{2}$ \\ ${ }^{1}$ Department of Pathology, Affiliated Hospital of Yanbian University, Yanji, \\ Jilin, China \\ ${ }^{2}$ Center of Morphological Experiment, Medical College of Yanbian University, \\ Yanji, Jilin, China \\ *These authors contributed equally to this study. \\ Corresponding author: X.D. Li \\ E-mail: lixdvip@126.com
}

Genet. Mol. Res. 14 (2): 5496-5500 (2015)

Received November 27, 2014

Accepted April 17, 2015

Published May 22, 2015

DOI http://dx.doi.org/10.4238/2015.May.22.20

\begin{abstract}
The objectives of this study were to observe the changes in expression of ErbB-3 binding protein (Ebp1) in cervical cancer and to investigate their clinic significance. We detected the expression level of Ebp 1 in cancerous and adjacent tissues from 56 patients with cervical cancer. We identified $21 \mathrm{Ebp} 1$ positive samples (37.5\%) from among the 56 cervical cancer tissue samples and 5 Ebp1 positive samples $(8.9 \%)$ in the corresponding adjacent tissues; the difference was statistically significant $(\mathrm{P}<0.05)$. No statistically significant $(\mathrm{P}>0.05)$ differences in the rates of positive Ebp1 expression were found between patients under 60 years of age and those equal to or over this age. No statistically significant differences $(\mathrm{P}>0.05)$ were found between patients whose tumor diameters were under $5 \mathrm{~cm}$ and those with tumor diameters over $5 \mathrm{~cm}$. No statistically significant differences $(\mathrm{P}>0.05)$ in the Ebp1 positive rates were found among the cervical cancer samples when stratified by grade (I, II, or III). Together, these results demonstrate that Ebp1 protein expression is upregulated in cervical cancer tissues but is not related to clinical pathologic factors such as patient age or tumor
\end{abstract}


size or differentiation level, suggesting that Ebp1 plays an important role in the genesis and growth process of cervical cancer.

Key words: Epidermal growth factor receptor; Ebp1 protein; Cervical cancer

\section{INTRODUCTION}

Cervical cancer is the second most common malignant disease among women around the world. The genesis and growth process of cervical cancer have close relationships with the expression and regulation of oncogenes and anti-oncogenes. Ebp1 is a recently identified intracellular ErbB-3 binding protein and its abnormal expression has been associated with tumors such as breast and prostate carcinomas (Hamburger 2008). In this study, we observed the expression changes of Ebp1 in cervical carcinoma and investigated their clinic significance.

\section{MATERIAL AND METHODS}

\section{Clinical materials}

We selected 56 patients with cervical cancer from those seen at the Affiliated Hospital of Yanbian University from November 2004 to November 2012. All patients were diagnosed by physical examination. None of the selected patients had been treated with chemoradiation prior to surgery and the tumor tissues and the normal adjacent tissues used in this study were resected during surgery. Among the patients, 34 were under 60 years old and 22 were equal to or over this age; the tumor diameters were under $5 \mathrm{~cm}$ in 17 patients but were equal to or over $5 \mathrm{~cm}$ in the other 39 patients. With respect to tumor differentiation status, 15 tumors were Edmondson grades I and II and the other 41 tumors were classified as grade III. Specimens were fixed with $10 \%$ formalin and embedded in paraffin; they were then sliced into $4-\mu \mathrm{m}$-thick sections for the following experiments.

\section{Methods}

The streptavidin-peroxidase immunohistochemisty method was performed as follows: The sample sections were deparaffinized with dimethyl benzene and dehydrated with an ethanol gradient series, followed by antigen retrieval by boiling the tissue sections in 0.01 $\mathrm{M}$ citrate buffer, $\mathrm{pH}$ 6.0, for $10 \mathrm{~min}$ and then naturally cooling them. Endogenous peroxidase activity was inactivated with $3 \% \mathrm{H}_{2} \mathrm{O}_{2}$ and the tissue sections were rinsed 3 times with phosphate buffered saline (PBS). Sections were incubated in a normal blocking solution of PBS with $10 \%$ normal goat serum and monoclonal anti-Ebp1 (1:100, abcam, Ltd, UK) overnight at $4^{\circ} \mathrm{C}$. After washing in PBS, sections were incubated with biotin-conjugated goat anti-rabbit $\operatorname{IgG}$ at $37^{\circ} \mathrm{C}$ for $2 \mathrm{~h}$ and then incubated in avidin-biotin complex solution for 1 hour at room temperature. Finally, sections were placed in 3,3'-diaminobenzidine tetrahydrochloride and viewed and photographed with a light microscope (Nikon Eclipse 80i, Nikon, Tokyo, Japan). Sections provided by the reagent company were used as positive controls and sections in which the primary antibody had been replaced by PBS were used as the negative control. Ebp1 positive cells were confirmed by the observation of buffy grains in the cytoplasm. For each 
sample, 5 fields were randomly selected under high power (400X) for observation, and 200 cells were counted in each field. The percentages of positive cells were counted, and the section was considered to be Ebp1 positive when the average number of positive cells exceeded $20 \%$.

\section{Statistical analysis}

Data were analyzed by the $\chi^{2}$ test utilizing the SPSS15.0 statistics software (SPSS, Chicago, IL, USA). A P value $\leq 0.05$ was considered to be statistically significant.

\section{RESULTS}

Among the 56 samples obtained from patients with cervical cancer, 35 were determined to be Epb1 negative (Figure 1A) and 21 to be Ebp1 positive (Figure 1B); the positive percentage was $37.5 \%$. Among the tumor-adjacent samples, 51 were found to be Epb1 negative and 5 were Ebp1 positive (Figure 1C); the positive percentage in this group was $8.9 \%$. The difference between the rates of Ebp1 positive samples among the two groups was statistically significant $(\mathrm{P}<0.05)$. The relationships between the expression of the Ebp1 protein and the clinical pathologic parameters of cervical cancer are displayed in Table 1. We can see that no statistically significant $(\mathrm{P}>0.05)$ differences in Ebp1 expression were found between patients under 60 years of age and those at this age or older. No statistically significant $(\mathrm{P}>0.05)$ differences were found in Ebp1 expression for patients with tumor diameters under $5 \mathrm{~cm}$ and those with tumors over $5 \mathrm{~cm}$. Furthermore, no statistically significant differences $(\mathrm{P}>0.05)$ in Ebp1 expression were found among the cervical cancer samples based on grade (I, II, or III).
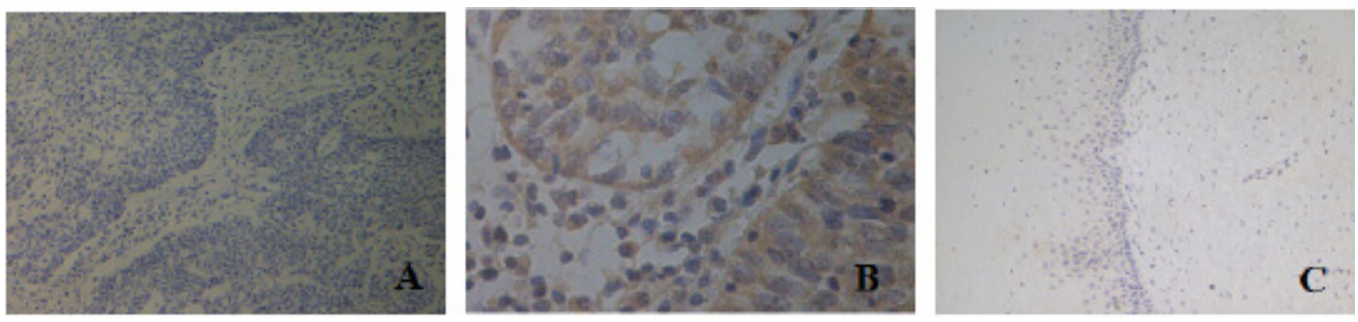

Figure 1. A. Negative Ebp1 protein expression in cervical cancer tissue; B. Ebp1 protein positive expression in cervical cancer tissue; $\mathbf{C}$. negative Ebp1 protein expression in normal tissue adjacent to carcinoma.

Table 1. Association between Ebp1 protein expression and clinical pathological parameters in cervical cancer.

\begin{tabular}{|c|c|c|c|}
\hline Clinical pathological parameters & $\mathrm{N}$ & Ebp1 positive & $\mathrm{P}$ \\
\hline \multicolumn{4}{|l|}{ Age (years) } \\
\hline$<60$ & 34 & 12 & \multirow[t]{2}{*}{$\mathrm{P}>0.05$} \\
\hline$\geq 60$ & 22 & 9 & \\
\hline \multicolumn{4}{|l|}{ Tumor size $(\mathrm{cm})$} \\
\hline$<5$ & 17 & 7 & \multirow[t]{2}{*}{$\mathrm{P}>0.05$} \\
\hline$\geq 5$ & 39 & 14 & \\
\hline \multicolumn{4}{|l|}{ Degree of differentiation } \\
\hline I, II & 15 & 6 & \multirow[t]{2}{*}{$\mathrm{P}>0.05$} \\
\hline III & 41 & 15 & \\
\hline
\end{tabular}




\section{DISCUSSION}

The role of epidermal growth factor receptors (EGFRs) (especially ErbB-1and ErbB-2) in the process of tumor formation and development has been previously discussed in the literature. Members of the EGFR family have been shown to be overexpressed in tumors such as breast carcinoma, ovarian cancer, and prostate carcinoma (Liu et al., 2007). Ebp1 is an ErbB-3 membrane-proximal region binding protein and is also a member of the proliferation related PA2G4 family. The Ebp1 protein can inhibit growth and proliferation and induce differentiation in tumor cells originating from breast carcinoma and carcinoma of the prostate which are positive for ErbB-2/ErbB-3 expression (Lessor et al., 2000; Zhang et al., 2008), suggesting that Ebp1 is a downstream effector molecule in the ErbB-3 signaling pathway. In addition, Cui et al. (2010) have found that the expression level of the Epb1 protein in carcinoma of the gastric cardia tissues was substantially lower than that in normal cardia tissues. Another study has shown that the Ebp1 expression in tumor-adjacent tissues was markedly higher than that observed in the adenoid cystic carcinoma tissues of the salivary glands (Sun et al., 2010). These experiments suggested that the Ebp1 protein could inhibit the growth and proliferation of tumor cells. On the other hand, recent studies have found that the rate of clonal colony formation of NIH3T3 cells increased following transfection with the Ebpl gene, suggesting that an exogenous increase of Ebpl can facilitate cell hyperplasia (Xu et al., 2008). These converse results might be associated with the expression of different portions of the Ebpl gene. The expression of the two isomers (p42 and $\mathrm{p} 48$ ) of Ebp 1 each plays a different role in cell proliferation. The $\mathrm{p} 48$ isomer is localized to the cytoplasm and the nucleus and its over-expression facilitates cell growth, whereas p42 is localized in the nucleus and its over-expression inhibits cell growth (Liu et al., 2006). The expression levels of the two subtypes are different in various tissues and so are their roles in regulating the growth and differentiation of tumor cells.

Previous studies have confirmed the high expression of ErvB-2 and ErbB-3 in cervical cancer tissues (Bacaksiz et al., 2008). This study found that the ErbB-3 binding protein Ebp1 is also highly expressed in cervical cancer tissues, suggesting that Ebp1 might be associated with the formation and development of cervical cancer. In addition, we have observed that the overexpression of the Ebp1 protein was unrelated to clinical pathologic factors such as patient ages and tumor size. Although Ebp1 was independently related to tumor progression, the mechanisms responsible for upregulation of Ebp1 levels in cervical cancer remain to be determined. However, assessment of Ebp1 protein expression status in cervical cancer patients by IHC will be useful in early detection.

\section{Conflicts of interest}

The authors declare no conflict of interest.

\section{ACKNOWLEDGMENTS}

Research supported by the Project of Education Department of Jilin province in China (\#2013-11). 


\section{REFERENCES}

Bacaksiz A, Sahin FI, Bilezikci B and Yilmaz Z (2008). Determination of HER-2/Neu status in hepatocellular carcinoma cases. Genet. Test. 12: 211-214.

Cui LL, Zhu MY, Chen MH, Zhang J, et al. (2010). Ebpl protein expression and clinical significance in cardiac cancer. Chin. J. Lab. Diagn. 14: 419-422.

Hamburger AW (2008). The role of ErbB3 and its binding partners in breast cancer progression and resistance to hormone and tyrosine kinase directed therapies. J. Mammary Gland Biol. Neoplasia 13: 225-233.

Lessor TJ, Yoo JY, Xia X, Woodford N, et al. (2000). Ectopic expression of the ErbB-3 binding protein ebp1 inhibits growth and induces differentiation of human breast cancer cell lines. J. Cell Physiol.183: 321-329.

Liu Z, Ahn JY, Liu X, Ye K (2006). Ebp1 isoforms distinctively regulate cell survival and differentiation. Proc. Natl. Acad. Sci. U.S.A.103: 10917-10922.

Liu Z, Liu X, Nakayama KI, Nakayama K, et al. (2007). Protein kinase C-delta phosphorylates Ebp1 and prevents its proteolytic degradation, enhancing cell survival. J. Neurochem. 100: 1278-1288.

Sun J, Yu YC, Tian Z, Gu ZY, et al. (2010). Expression of ebp1 in adenoid cystic carcinoma and its clinic-pathologic significances. Fudan. Univ. J. Med. Sci. 37: 583-586.

Xu DY, Liu L, Li LC, Zheng J, et al. (2008). Effects of overexpression of ErbB-3 binding protein Ebp1 on growth and proliferation of NIH3T3 cells. Chin. J. Anat. 31: 764-766.

Zhang Y, Linn D, Liu Z, Melamed J, et al. (2008). EBP1, an ErbB3-binding protein, is decreased in prostate cancer and implicated in hormone resistance. Mol. Cancer Ther. 7: 3176-3186. 